\title{
Remote monitoring in marine production systems
}

\author{
Authors: Janne Kool \& Miriam Bernard (2019)
}

DOI: https://doi.org/10.18174/551596

Funding: The funding that lead to this publication stems from two KB projects; KB-38-001005 Autonomous Collaborative Robots, part of Data Driven High Tech programme (JK), and KB36-2C4 Marine lower trophic food systems (MB).

This report is published under CC-BY-NC-SA 4.0 copyright.

1. Introduction

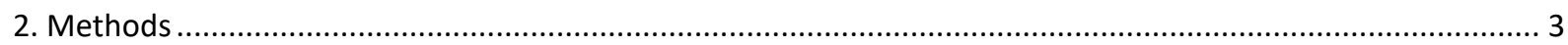

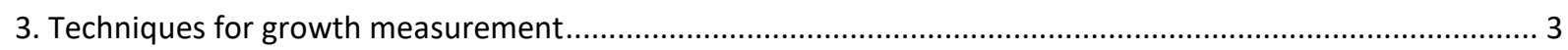

Method 1: Estimating biomass by comparing irradiance inside and outside the farm ................................ 3

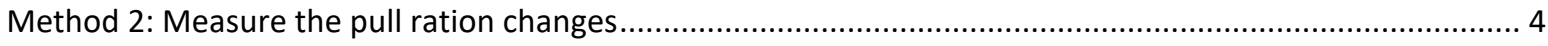

Method 3: Measuring the difference in angles between a seeded rope and an non-seeded rope.................. 6

Method 4: Using underwater imagery techniques to estimate the biomass production .............................. 6

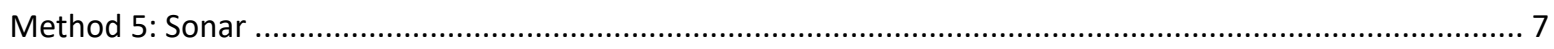

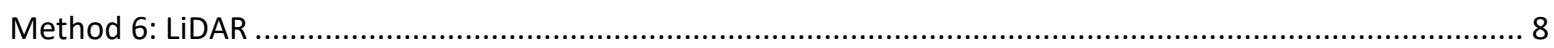

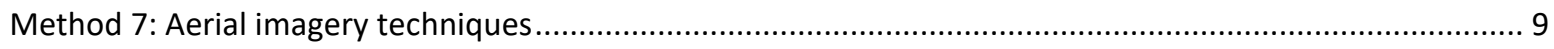

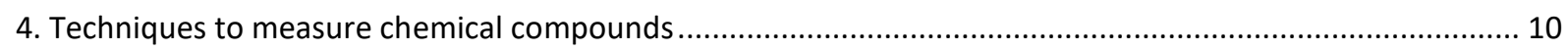

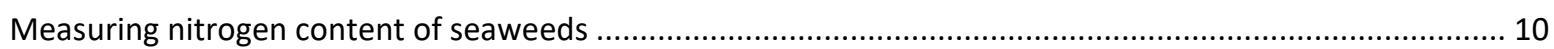

Method 8: Measuring nitrogen content by hyperspectral imaging ..................................................... 10

Method 9: Measuring nitrogen content by fluorescence sensors ...................................................... 10

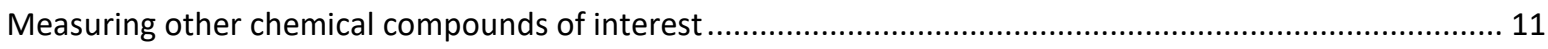

5. Modelling seaweed growth and composition based on environmental measurements........................... 11

6. Challenges of working in salt water under offshore conditions........................................................... 12

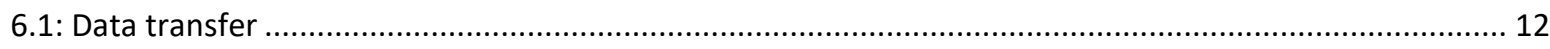

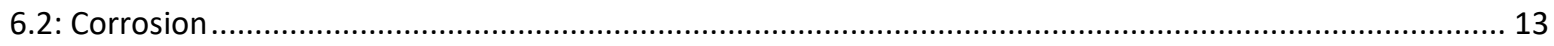

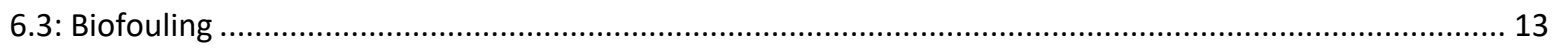

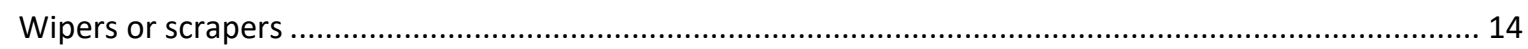


Ultrasonic . 15

7. Ranking of methods according to defined criteria 15

\section{Introduction}

Global seaweed aquaculture is rapidly expanding (Buschmann et al. 2017) and both the produced biomass as well as the associated financial value have increased exponentially over the last decades (Food and Agriculture Organization of the United Nations). Due to their high nutritional value seaweeds have a potential to cover the increasing protein demand of the world's population (Van denHoek and Bayoumi 2018). Moreover, seaweed farming is often regarded as a sustainable form of food production (Hughes et al. 2012; Sondak et al. 2017) as it can also help in climate change mitigation through the conversion of $\mathrm{CO}_{2}$ to carbon-rich biomass. Seaweed production may also contribute to a circular economy by taking up nutrients introduced into the ocean through rivers and estuaries which can be used for the production of macroalgal biomass.

Seaweeds can not only serve as a food source, but there are also other potential uses for the biomass including fertilizers, animal feed and cosmetic or medical products (McHugh 2003; Loureiro et al. 2015). Furthermore, seaweeds have a high potential for the sustainable production of bioethanol and biogas (Adams et al. 2009; Chen et al. 2015).

Traditionally, seaweed farming has mainly been conducted in Asian countries while the seaweed use in Europe was based on wild harvesting (Food and Agriculture Organization of the United Nations). However, collecting the biomass is not always done in a sustainable way, it is challenging in rocky reefs and strongly dependent on the weather conditions. Furthermore, the harvested biomass is often a mix of species which makes processing complicated (Hafting et al. 2012). Therefore, during the last decades seaweed aquaculture has also increased in Europe (Barbier et al. 2019). In the Netherlands, the majority of commercial seaweed production currently takes place in the Eastern Scheldt but a significant expansion of the Dutch seaweed sector is foreseen offshore in the Dutch North Sea either in stand-alone cultures or in multi-use settings with other maritime activities (van den Burg et al. 2013; Jansen et al. 2016).

While the step towards commercial offshore seaweed cultivation will provide a large amount of space suitable for growing algal biomass, it comes with its own challenges. For instance, the cultivation system has to be able to withstand harsh environmental conditions (Buck and Buchholz 2004). Furthermore, continuous monitoring of the seaweed growth and biomass production is very expensive. However, frequent monitoring is not only necessary in order to assure that the seaweed farm is not being destroyed by other maritime activities, such as fishing boats, but also to follow the growth of the seaweeds in order to determine the optimal harvesting time. The latter may not only depend on the amount of biomass, but also on the chemical composition of the seaweeds. For the processing industry it is desirable to obtain uniform seaweed biomass (Hafting et al. 2012). However, previous studies have shown that the biochemical composition of seaweeds changes significantly over the cultivation season (see experiments performed by van der Werf \& van der Meer in the North Sea Innovation lab). If, for instance, seaweed biomass with a specific protein concentration is desired for feed purposes, the optimal harvesting time should be determined by the protein content. 
In order to enable a continuous monitoring of offshore seaweed farms, it is necessary to develop methods and techniques that can be used remotely to measure both the growth of seaweeds and the amount of specific biochemical compounds. These methods should provide real-time data to inform the farmer about what is happening in the farm without the necessity of direct visits.

In this following report, we present and discuss different methodologies for remote monitoring of the growth and composition of seaweeds. This study will contribute to the development of offshore seaweed aquaculture and the information presented here could be of interest for actors of the seaweed sector and policy makers.

\section{Methods}

A longlist of techniques for remote monitoring of growth and composition of seaweeds was generated by literature reviews and discussion with the following experts from Wageningen Plant Research:

- Pepijn van Oort (Agrosystems Research, expert on modelling, WUR)

- Bert Meurs (Agrosystems Research, expert on nitrogen measurements in terrestrial systems, WUR)

- Adrie van der Werf (Agrosystems Research, expert on seaweed research, WUR)

- Ingrid van der Meer (Bioscience, expert of seaweed biochemistry, WUR)

- Nicola Grasso, Pieter Aalberts, Floor Spaargaren (Marin)

The presented methods are discussed and ranked according to their potential and applicability in offshore seaweed farms.

\section{Techniques for growth measurement}

In this chapter we describe potential techniques for measuring seaweed growth.

\section{Method 1: Estimating biomass by comparing irradiance inside and outside the farm}

The growing seaweed biomass is directly affecting light availability within and below the farm. Quantum sensors could be deployed on ropes inside and outside of the farm, respectively. Incoming light is measured at both positions and the ratio between the two measurements could be used as a relative measure for the amount of biomass on the rope inside of the farm.

Expected difficulties:

1. The presence of cultivation structures (buoys and lines) is decreasing the light availability inside of the farm independent of the growing biomass. Therefore, the method needs to be calibrated at to before the biomass is growing. This has to be done at each farm independently.

2. The optimal depth for the light sensors needs to be determined. If the sensors are deployed below the farm, little light may be detected. On the other hand, sensors may be covered by the growing fronds when placed at intermediate depth in the farm.

3. Sensors are rapidly overgrown by fouling organisms, making measurements unreliable after a certain amount of time. It is therefore necessary to include an automated cleaning procedure. 
4. This method measures the presence of all biomass, i.e. not only the cultivated seaweed, but also wild seaweeds settling and growing on the cultivation ropes.

5. A standardized transferrable method has to be developed for reliable monitoring of seaweed farms.

Open questions:

1. An estimation of the local turbidity is necessary in order to determine the optimal distance between the reference sensor and the farm.

2. The sensor-bearing ropes can get entangled during storms or times of high waves which will make the measurements unreliable. Several sensors should be deployed in the farm and a weight could be added to the bottom of the ropes in order to keep them vertically. It needs to be determined how many sensors are necessary to obtain a robust measurement.

Advantages and disadvantages:

1. This technique is a relative method, as measurements inside and outside of the farm are compared. Therefore, it could be used even under changing environmental or seasonal conditions.

2. A difficulty may be the deployment of additional equipment outside the farm, including both risks and bureaucracy coming along with it.

\section{Method 2: Measure the pull ration changes}

When seaweeds are growing, it is expected that the pulling force on the rope will increase directly correlated with biomass. Force sensors (Fig. 1) are connected to several seeded and non-seeded droppers and the ratio can be used for a relative estimation of biomass.

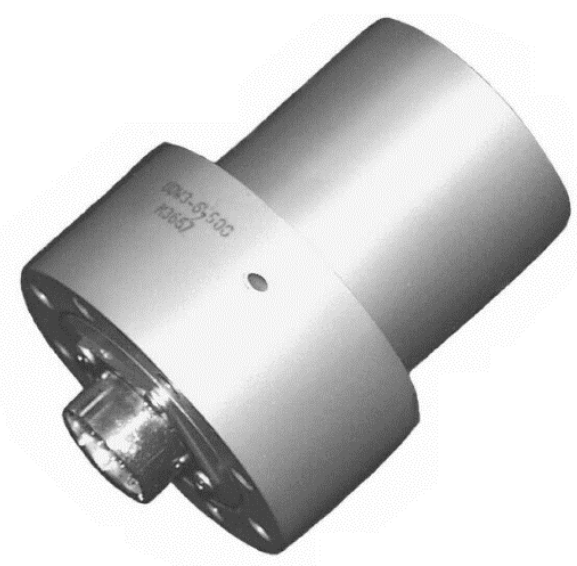

Fig. 1: Force sensor for underwater measurements for measuring forces up to 4450N (UDW3, A-Tech instruments Ltd., Canada).

Expected difficulties:

1. Measuring weight underwater could be difficult due to Archimedes law. However, it could be measured as a difference in pull when lines are moving in the water column and be expressed relatively as the ratio between seeded and non-seeded lines.

2. High wave action will also affect the pulling forces. This has to be considered when interpreting the data.

3. A standardized transferrable method has to be developed for reliable monitoring of seaweed farms. 
Open questions:

1. Is current speed underwater dependent of the current only or does wind/storm affect is as well?

2. What exactly is growing on unseeded droppers, can it be assumed that no kelp is growing there?

3. The sensor-bearing ropes can get entangled during storms or times of high waves which will make the measurements unreliable. It needs to be determined how many sensors are necessary to obtain a robust measurement.

4. What is the order of magnitude of the forces measured generally and during high currents speed? The instruments' measuring range has to be chosen accordingly..

5. Previous experiments by WMR have shown that mussels are settling in high numbers on seaweed cultivation ropes. Are amounts of mussels found on the seeded and non-seeded lines comparable?

6. Is it true that the ratio between a seeded and unseeded line is independent of the amount of mussels attached? According to Coulomb's law:

$$
F_{\text {line }} \leq \mu \times F_{n}
$$

Where $F_{n}$ is the normal force hence $m^{*} g$

So

$$
\frac{F_{\text {seededline }}}{F_{\text {unseededline }}}=\frac{\mu_{\text {seededline }} \times m_{\text {seededline }}}{\mu_{\text {unseededline }} \times m_{\text {unseededline }}}
$$

We assume:

$$
\begin{gathered}
m_{\text {seededline }}=m_{\text {unseededline }}+m_{\text {biomass }} \\
\mu_{\text {seededline }}>\mu_{\text {unseededline }}
\end{gathered}
$$

And hence we expect that the ratio $\frac{F_{\text {seededline }}}{F_{\text {unseededline }}}$ grows with increasing biomass.

Advantages and disadvantages:

1. This is a direct measurement within the farm and no additional structure is needed for measurements outside of the farm.

2. The equipment used for this method may be less susceptible to biofouling. Even if organisms settle on the instrument, it is not expected to affect measurements.

3. The distance from the sensors to a data collection buoy, and therefore the distance of underwater data transfer, is relatively short as instruments will be deployed close to the surface.

4. In a farm design where the droppers are connected to a bottom line (as used in the North Sea Innovation lab), an application of this method is more complicated. 


\section{Method 3: Measuring the difference in angles between a seeded rope and an non-}

\section{seeded rope}

When ropes are moving in the water column due to wave action or currents, it is expected that the angle between seeded and non-seeded lines is different. Measuring the angles by a spirit meter or inclinometer (Fig. 2) could be used as a relative way to determine biomass by comparing seeded and non-seeded ropes. Unseeded ropes are expected to lie almost horizontally in the water under high current, whereas kelp growth on a rope will lie in the water column in a different angle.

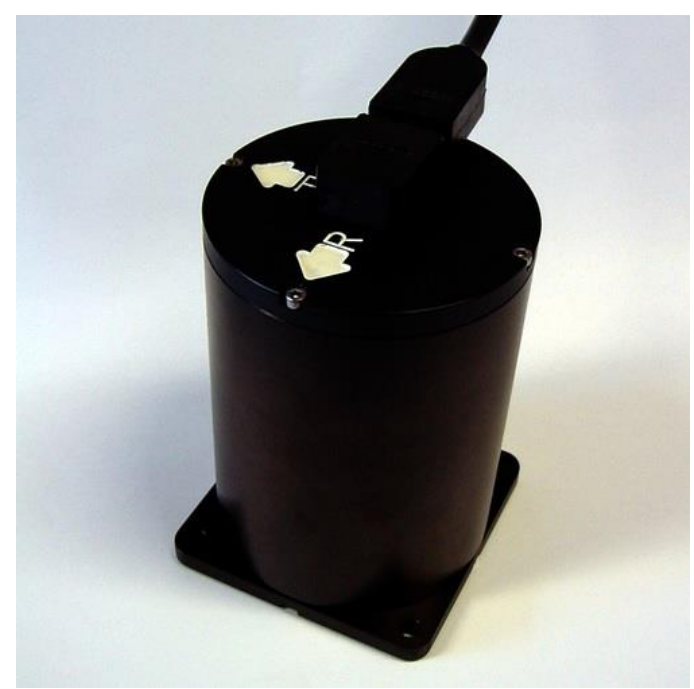

Fig. 2. OceanTILT inclinometer (OceanTools, UK).

Expected difficulties:

1. Angles are not constant and will fluctuate not only with currents but also with wave movements. In order to produce reliable results, several seeded and non-seeded ropes should be compared.

2. A standardized transferrable method has to be developed for reliable monitoring of seaweed farms.

Open questions:

1. How many replicates are necessary to provide a robust measurement?

Advantages and disadvantages:

2. No additional structure is needed for measurements outside of the farm.

3. The equipment used for this method may be less susceptible to biofouling. Even if organisms settle on the instrument, it is not expected to affect measurements.

\section{Method 4: Using underwater imagery techniques to estimate the biomass production}

Underwater image and video techniques could be used to assess the growth visually. This could either be done by cameras attached to the cultivation ropes or by autonomous underwater vehicles, such as drones.

Expected difficulties:

1. Cameras have a high demand of battery life. Continuous energy supply needs to be ensured.

2. Video techniques produce large data files which need to be transferred underwater. 
3. Lenses get easily overgrown, making measurements less usable. Thus, an automated cleaning system needs to be included.

4. Visibility may be bad under high sediment loads or turbidity.

5. A standardized transferrable method has to be developed for monitoring of seaweed farms.

Questions to answer:

1. Immobile cameras: how and where should they be attached on the rope? Should they be facing horizontally or upwards?

2. What is the best time point for taking photos/videos, for instance during the turning of the tides as recommended by Tonk et al. (2019)?

Advantages and disadvantages:

1. Underwater video techniques provide a direct view on what is happening in the farm.

2. Numerous models of underwater cameras are available.

3. This technique could simultaneously be used for other purposes, such as biodiversity assessments.

4. Cameras have a high energy demand.

\section{Method 5: Sonar}

Objects can also be detected underwater using sound. A sonar (Fig. 3) could be deployed inside of a seaweed farm to obtain a sonar image of the farm and estimate the biomass production. Sonars measure in cones and need to be located optimally in order to obtain a horizontal view on the seaweed biomass. Multi-beam sonar has been used previously to map natural kelp forests (McGonigle et al. 2011; Young et al. 2015).

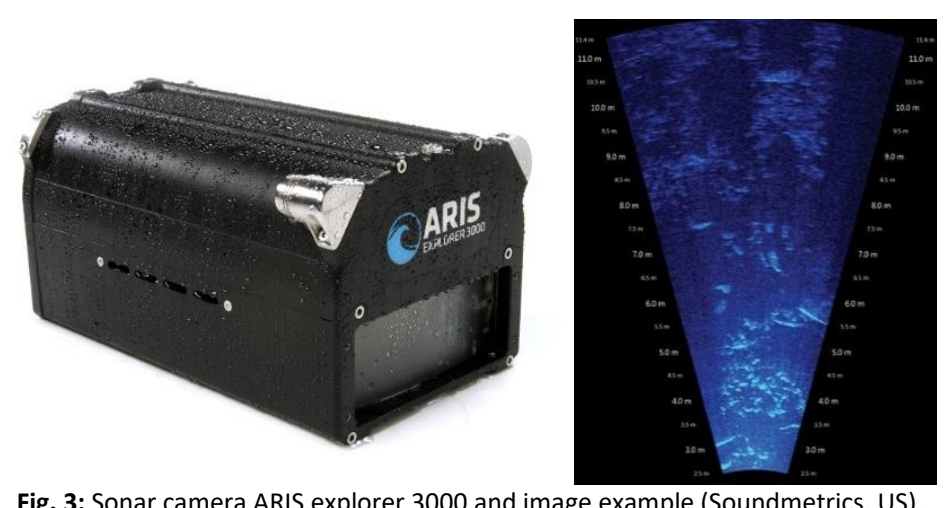

Expected difficulties:

1. Images may be difficult to interpret by eye.

2. The sonar needs to be stabilized to make sure that the axis stays horizontally in order to ensure the comparability of measurements.

3. The relative orientation of the kelps and the farm design affect how much can be seen on sonar images. It is likely that all kelp fronds are oriented in the same direction due to currents which needs to be considered for data analysis.

4. Sonar has a high energy demand and large data files need to be transferred. The sonar could be directly attached to a buoy for broadcasting the data in order to avoid expensive and complicated underwater data transfer. 
5. A standardized transferrable method has to be developed for monitoring of seaweed farms.

Open questions:

1. How can the sonar be mounted in a stable way? If images are skew the data interpretation and comparison will be difficult.

2. What is the difference between single and multibeam sonar and which is best to use for seaweed farm monitoring?

Advantages and disadvantages:

1. There is a considerate amount of literature available investigating on monitoring of wild kelp populations using this technique.

2. Sonar devices have a higher spatial coverage than video cameras, especially in turbid waters like the North sea.

3. Commercially available sonar cameras produce detailed images of the surroundings (e.g. http://soundmetrics.com).

\section{Method 6: LIDAR}

LiDAR (Light Detection and Ranging) uses a high-frequency light pulse and interprets the return time of the beam for area estimation. This method could be used in a similar way as sonar to estimate seaweed biomass.

Expected difficulties:

1. Light cannot travel efficiently in water. This can be a problem especially in turbid waters.

2. The LiDAR needs to be stabilized to make sure that the axis stays horizontally in order to ensure the comparability of measurements.

3. The relative orientation of the kelps and the farm design affect how much can be seen on LiDAR images. It is likely that all kelp fronds are oriented in the same direction due to currents which needs to be considered for data analysis.

4. LiDAR has a high energy demand and large data files need to be transferred. The sonar could be directly attached to a buoy for broadcasting the data in order to avoid expensive and complicated underwater data transfer.

5. A standardized transferrable method has to be developed for monitoring of seaweed farms.

Open questions:

1. What distances can be measured by LiDAR within a seaweed farm?

2. Is LiDAR a useful tool in turbid waters?

Advantages and disadvantages:

1. Different light sensors can be deployed simultaneously, providing a wide range of data.

2. Applicability in the turbid North Sea is unsure. 


\section{Method 7: Aerial imagery techniques}

Satellite images or aerial digital multispectral imaging systems (DMSC) taken by drones or aircrafts can be used to estimate seaweed biomass from above. This method is mainly suitable for floating seaweed biomass and has been used to map wild seaweed populations (Fig. 4, Uhl et al. 2016). Its applicability for seaweed farms has yet to be tested.

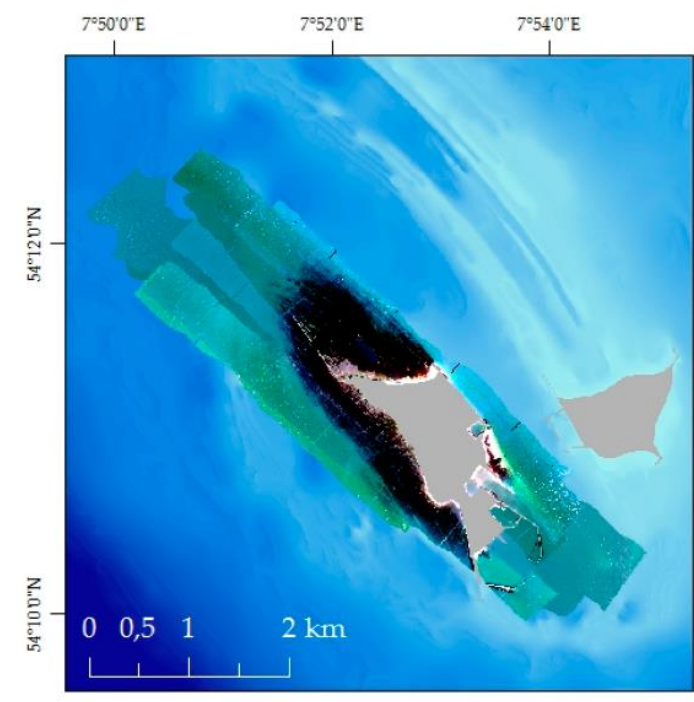

(a)

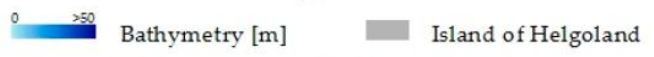

Selected flight stripes as stretched true colour RGB.

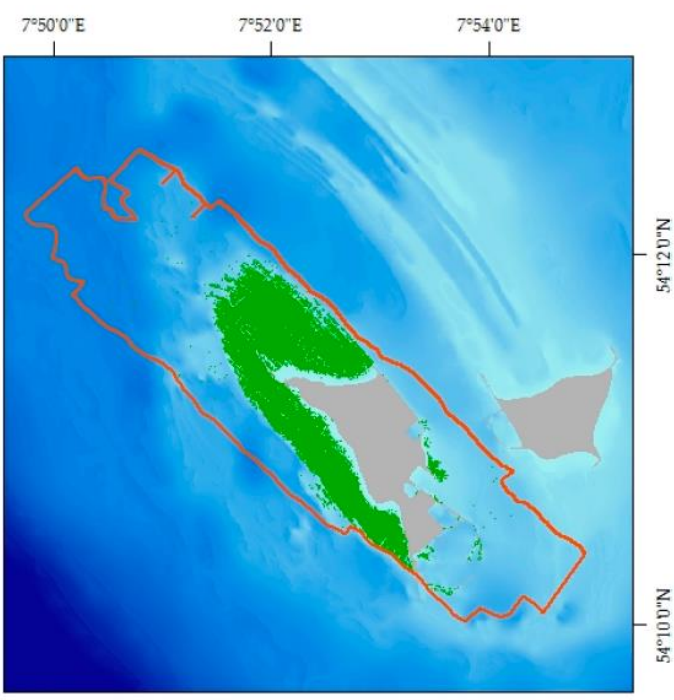

(b)

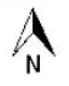

Projected Coordinate System: WGS 1984 UTM Zone 32N

Fig. 4. True colour images obtained by a hyperspectral AisaEAGLE system on an aircraft. Images of (a) selected flight stripes and (b) kelp detected by an algorithm (Uhl et al. 2016).

Expected difficulties:

1. The visibility of the seaweed farm on aerial images has to be assessed. It is not clear whether seaweeds cultivated on vertical ropes are visible on aerial images.

2. Satellite images: The visibility on satellite images depends strongly on the weather. Unfavourable weather conditions could make the images useless for biomass estimation. Furthermore, the temporal resolution of the satellite images may be too low. For instance, the temporal resolution of Landsat 7 is 16 days, which may not be frequent enough for continuous monitoring.

Questions to answer:

1. Are seaweed farms visible on aerial and satellite images?

2. If so, what is the optimal altitude for aerial DMSC?

Advantages and disadvantages:

1. Satellite images are easily accessible and multispectral images can not only provide information on the biomass, but also on the seaweed health.

2. Using drones or aircraft may be very expensive. 


\section{Techniques to measure chemical compounds}

In this chapter we describe potential techniques for measuring biochemical compounds of seaweed.

\section{Measuring nitrogen content of seaweeds}

In many cases, the nitrogen content can be directly correlated to other compounds of interest. For instance, protein content of seaweeds is estimated by using the nitrogen-to-protein conversion factor of 5 (Angell et al. 2016). In Ulva sp., also other compounds such as ash, starch or fiber can be correlated with the nitrogen content (pers. comm. A. van der Werf). However, this correlation has not been observed in Saccharina latissima.

Monitoring the protein content could be of interest when seaweed is used as food or feed. Additionally, an estimation of the ash content could be interesting, as high amounts of ash reduce the efficiency of extraction procedures (Milledge et al. 2014). As these compounds have been shown to vary significantly over the growth period (pers. comm. A. van der Werf), monitoring them could help to choose the most suitable harvesting time point depending on which end product is desired.

\section{Method 8: Measuring nitrogen content by hyperspectral imaging}

The nitrogen content of grass and other terrestrial crops can be measured using hyperspectral imaging. Light reflectance of the crop is measured between 400 and $1000 \mathrm{~nm}$.

Expected difficulties:

1. Hyperspectral imaging is expected to be difficult underwater, especially in turbulent water. In order to overcome this problem seaweed could be lifted out of the water mechanically.

Open questions:

1. Is it possible to use hyperspectral imaging techniques underwater?

Advantages and disadvantages:

1. This method gives a direct insight into the biochemistry of the seaweed biomass.

2. Measuring the nitrogen content with this method is less expensive than performing chemical analysis.

\section{Method 9: Measuring nitrogen content by fluorescence sensors}

Fluorescence sensors are often used to study crop physiology, but can also be used to determine the nitrogen content. Chlorophyll molecules absorb energy at a given wavelength, whereas part of the energy is dissipated by light emission at longer wavelengths. This amount can be measured as fluorescence emission.

Expected difficulties:

1. Fluorescence measurements under water are more difficult than on land. However, the Water-PAM (Waltz, Germany) could be tested for this purpose.

Open questions: 
1. How reliable are underwater fluorescence measurements?

\section{Measuring other chemical compounds of interest}

Next to nitrogen, there are other chemical compounds that could be interesting to monitor. For instance, the cell walls of seaweeds contain gelling polysaccharides of commercial interest, such as alginate, agar or carrageenan. Next to food products, these polysaccharides are also used in the biomedical field and tissue engineering (Venkatesan et al. 2017). Polysaccharide content in seaweeds is determined by complex extractions protocols in laboratories (Barros et al. 2013; Schiener et al. 2014; Ganesan et al. 2015) and to our knowledge no sensors for measuring polysaccharides are available so far.

Another interesting compound to monitor is iodine. The iodine content in kelps can quickly exceed the upper limit of $600 \mu \mathrm{g} /$ day set by the European Food Safety Authority. In order to assure a possible application of the seaweed biomass for food or feed, iodine content could be monitored over the entire growth period. lodine content can be measured by isotope dilution inductively coupled plasma mass spectrometry (ICP-MS, Haldimann et al. 2005) or inductively coupled plasma-optical emission spectrometry (ICP-OES, Schiener et al. 2014). Furthermore, colorimetry is used to determine iodine content in water samples (Dunn et al. 1993). To our knowledge, no sensors exist for measuring iodine in plant or seaweed tissue, but if a technique could be developed it would be of interest for the seaweed industry.

Next to polysaccharides and iodine, also the presence of contaminants, such as heavy metals, can prevent the use of seaweeds as food or feed. Arsenic is introduced into the oceans via natural and anthropogenic sources (Chilvers and Peterson 1987). It is present in seawater in inorganic compounds and marine organisms take it up and convert it into organic compounds (Ronan et al. 2017). The long-term uptake of inorganic Arsenic compounds can have serious health effects on the human body whereas the organic forms are not considered as toxic for the human body (Hughes et al. 2011). Concentration of inorganic arsenic is usually determined by high performance liquid chromatography coupled with mass spectrometry (HPLC, Ronan et al. 2017) or dynamic reaction cell mode (DRC, Ratcliff et al. 2016), but recently also a field kit has been developed for this purpose based on a simple extraction method and selective volatilisation (Bralatei et al. 2017). If this method can be further automized, it would represent a useful tool for remote monitoring of the inorganic arsenic content in seaweed cultivated in offshore farms.

\section{Modelling seaweed growth and composition based on environmental measurements}

Based on the kelp growth model developed by Broch et al. (Broch and Slagstad 2012; Broch et al. 2019), environmental conditions could be measured in a seaweed farm to calculate biomass production and biochemical contents.

The inputs of the model are temperature, light radiance, nitrogen concentration in the water and current speed, at point $(x, y, z, t)$. These parameters can be measured within a seaweed farm by sensors deployed in replicates.

The outputs of the model are wet and dry weight as well as carbon and nitrogen content in the tissue at a point $(x, y, y, t)$. These values can be calculated based on the data collected by the sensors. 
Expected difficulties:

1. Sensors are rapidly overgrown by fouling organisms, making measurements less reliable. It is therefore necessary to develop an automated cleaning procedure.

2. Feeding sensor data into the model has to be automated.

Questions to answer:

1. What are the spatial and temporal resolutions used for the model?

2. At which depth should the sensors be deployed? If sensors are deployed on the bottom, a majority of light is already absorbed by the biomass growing above, but the data could also be used for biomass estimation (see description of method 1).

3. How vulnerable is the model towards a lack of data? How useful is the data if one of the data sources is lost?

Advantages and disadvantages:

1. As the data deriving from this method is based on modelling and not on direct measurements, it may be less appealing for farmers.

2. All necessary sensors exist already and the method could be tested easily.

3. As a side effect of the measurements, biomass could be estimated by the light sensors (see method 1 ) if they are deployed in a reasonable way.

4. The underwater data stream has to be set up for a high number of sensors, which makes the system expensive and vulnerable.

\section{Challenges of working in salt water under offshore conditions}

\section{1: Data transfer}

Transferring data collected by the sensors through the water to the land is not possible on long distances and therefore has to be established via the air. A possible solution could be to send the data from the sensors to a local buoy which can then broadcast the information to the land. The information from the sensors could either be transferred by cables or underwater communication using sound. It is to be investigated which system is more robust and reliable.

Data transfer via cables: Underwater cables are commercially available (for instance by Leoni special cables $\mathrm{GmbH}$, Germany) which can transfer up to $6 \mathrm{kV}$, data, and resist pulling up to $100 \mathrm{kN}$. The risk of using underwater cables is that they could be destroyed by the rough offshore conditions or maritime activities which will disrupt data transmission until the cable is replaced.

Wireless data transfer: Underwater information can also be transmitted through radio signal or acoustic signals (see comparison in Table 1). In both cases the amount of data that can be transferred is relatively small.

There is a trade-off between the amount of data transmitted and the energy use of the sensor; if the sensor needs to process the data to some extent, for instance averaging over a day, then less data needs to be transferred, but the sensor itself uses more energy. 
Table 1: Comparison of distance and error by radio and acoustic signals.

\begin{tabular}{|c|c|c|}
\hline & Radio & Sound \\
\hline Distance & 50 to $500 \mathrm{~m}$ (Heideman et al. 2006) & $\begin{array}{l}\text { Between } 100 \mathrm{~m} \text { and } 1000 \mathrm{~km} \text {, the longer the } \\
\text { distance the smaller the bandwidth (Akyildiz 2005). }\end{array}$ \\
\hline Errors & smaller delay & $\begin{array}{l}\text { larger propagation delay about } 5 \text { times larger than } \\
\text { radio }\end{array}$ \\
\hline Others & $\begin{array}{l}\text { when frequency is low, antennas must be } \\
\text { large }\end{array}$ & \\
\hline
\end{tabular}

\section{2: Corrosion}

Corrosion is a threat for instruments deployed in seawater, especially for moving instrument parts. Therefore, it is recommended to use instruments especially built for the deployment in seawater which are made of corrosionresistant material. The corrosion on unprotected steel in the Dutch North Sea is up to $0.18 \mathrm{~mm}$ per year (Momber 2011). Since the instruments are only deployed for a few months during the cultivation season and can be well maintained and cleaned between cultivation periods, corrosion is not seen as a major challenge for remotemonitoring.

\section{3: Biofouling}

Biofouling on sensors, housing or support structures is often considered as a limiting factor in ocean monitoring (Delauney et al. 2010). A large number of organisms is involved in the biofouling process (Fig. 5, Yebra et al. 2004) and many parameters affect the speed and type of biofouling. During productive periods (so called blooms), biofouling can develop very rapidly in seawater and affect data quality within less than 2 weeks (Lehaitre and Compère 2008). As the shift in data is usually continuous, detecting a drift in measurements can be difficult. Biofouling organisms are especially problematic for optical and electrochemical sensors and can render measurements entirely unusable (Delauney et al. 2010). Commercially available techniques to prevent biofouling are presented here.

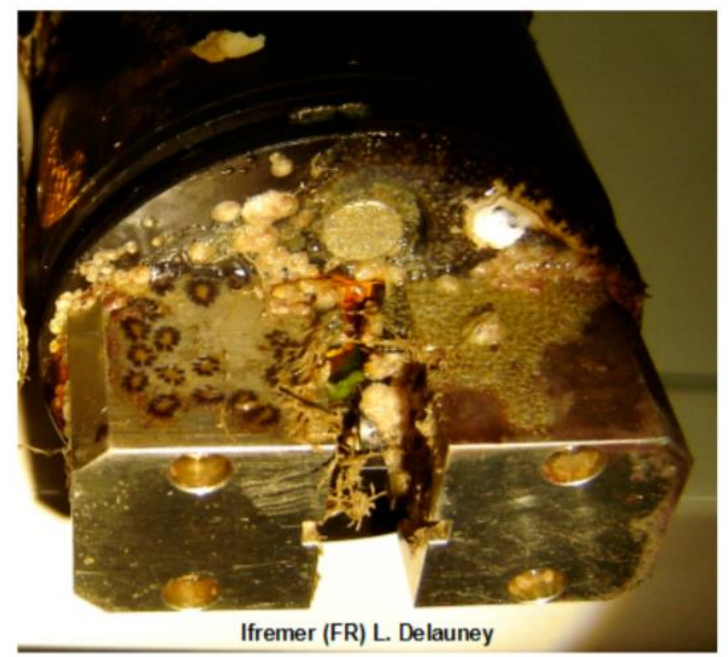

Fig. 5: Biofouling on a marine sensor deployed for 30 days in the North Sea close to Helgoland (Delauney et al. 2010) 


\section{Wipers or scrapers}

Wipers are already included in a number of oceanographic instruments and can be custom-adapted to other instruments. They can be operated by batteries and the wipe interval determines the battery life. For instance, wipers by Zebra Tech Ltd. (Fig. 6) can work in a one hour interval for over four months on battery. Wipers work efficiently as long as they are in a good physical condition, but the wiper mechanics needs to be robust enough to withstand harsh environmental conditions. Furthermore, wipers cannot be used for sensors with highly complex and delicate surfaces.

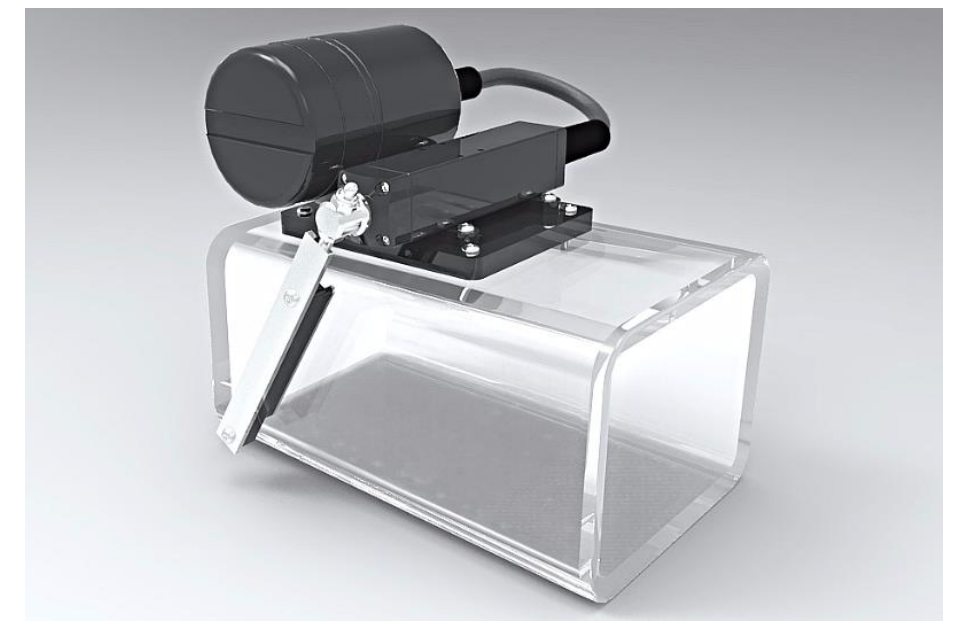

Fig. 6: Underwater housing with hydro-wiper (Zebra Tech Ltd., NZ)

\section{Chemical biocides}

Bis(tributylin)oxide (TBT) has been applied as an agent against biofouling, but this compound has a deleterious effect on the marine environment and should therefore no longer be used. Copper is also used to protect oceanographic sensors by preventing cell division of the fouling organisms. Furthermore, chlorination has been suggested for biofouling protection. Bleach is applied in fresh water monitoring, whereas electrolysis chlorination is for instance used for ferry box instruments. Electrolysis can be performed on a restricted area and little energy is necessary (Delauney et al. 2010).

UV

Ultraviolet light is an environmental friendly way to reduce biofouling and prevent an accumulation on the critical sensor surface. Commercially available UV antifouling devices, such as the UV Xchange (Fig. 7, Seabed BV, NL), are reliable and easy to attach to instruments like cameras and sensors. They work on a range of up to $10 \mathrm{~cm}$. 


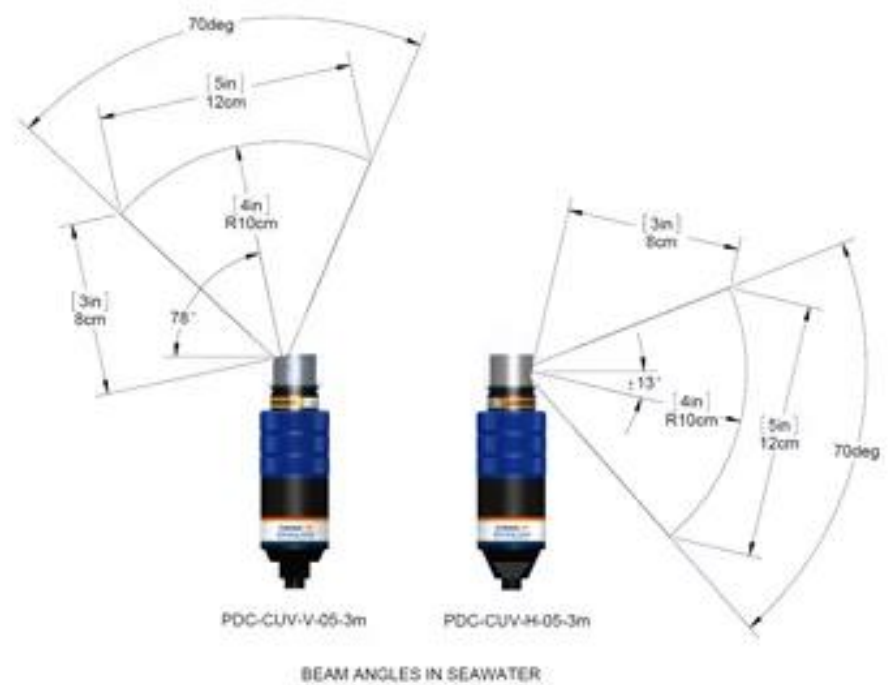

Fig. 7: UV antifouling device (UV XChange, Seabed BV, NL)

\section{Ultrasonic}

The use of ultrasonic prevents the settlement of biofouling organisms. The system needs to start on a clean surface and must operate without disruptions. Thus, a continuous energy supply is needed for this method. Once biofouling has started ultrasonic instruments are not a useful tool to remove it but growing speed can be decreased (information provided by Lamers Systems Care, NL, https://lscare.nl/working-principleultrasonic-anti-fouling/).

\section{Ranking of methods according to defined criteria}

In the discussion with Ingrid van der Meer and Adrie van der Werf it was pointed out that a remote monitoring of biochemical content of seaweeds is not advising at this moment due to a lack of information about the potential market for seaweed biomass and about seasonal changes of biochemical compounds in offshore grown seaweeds. It is not expected that seaweed will be the future source for extracted proteins, since the extraction process from seaweed biomass is inefficient due to high amounts of polysaccharides (pers. comm. Ingrid van der Meer). Furthermore, it has been shown for kelps from the North Sea Farm that protein content may not directly correlate with nitrogen content, which makes it very challenging to estimate the protein content based on the nitrogen-to-protein conversion factor. Ingrid van der Meer considered polysaccharides to be among the more interesting compounds to obtain from seaweeds. Adrie van der Werf pointed out that seaweeds can enhance productivity of terrestrial crops, but the active compound(s) have not been determined yet and can therefore not be targeted specifically in monitoring programs. Overall, it was concluded that biomass monitoring is of larger interest at this moment than monitoring of biochemical compound.

The realisation of data transfer was not taken into account for the ranking of the methods. Most methods are dependent on the underwater transfer of data and it has not been decided yet during this phase of the project how the transfer should and could be realised.

Finally, costs were not taken into account since a realistic estimation for the different methods was not possible.

The methods were ranked according to the following criteria: 
Robustness:

1. Number of components

2. Vulnerability to corrosion

3. Vulnerability to biofouling

Reliability:

4. Direct or derived measurement

5. Need for ground-truthing

Other criteria:

6. Availability of offshore robust measure equipment

7. Expected difficulty of data analysis

8. Dependence on the farm design

9. Distance of underwater data transfer

10. Number/severeness of assumptions made

We scored all the methods according to this criteria. Criteria 4 and 9 were considered as especially important. The question whether the measurement is direct or derived is important to convince farmers of the usefulness and reliability of the chosen method. The distance for underwater data transport is important as this point is seen as a major challenge when it comes to implementing the methods. Therefore, the score of these two criteria was weighted double. Finally, the number of assumptions made (10) was found most the critical and important criterion because it defines how realistic the success of a chosen method is. The score of this criterion was therefore weighted triple. All scores are presented in Table 2.

Based on our analysis we propose to further investigate and test the following four methods:

- $\quad$ Sonar (score: 31)

- Measuring the pull changes (score: 28 )

- Underwater cameras (score: 28$)$

- $\quad$ Model (score: 24)

Although aerial imagery received a high score in our ranking, we propose not to investigate this method further, as it is very unsure whether kelp biomass cultivated under water is visible from above, even under moderate weather conditions. Furthermore, the low temporal resolution of satellite images prevents frequent monitoring of a farm.

Sonar and LiDAR received the same score, however, as sounds travels better through water, in particular the turbid water of the North Sea, we consider sonar the better method for biomass assessments. Sonar is also well developed for underwater observations.

The model did not receive a high score but we propose to consider it anyway since all sensors are available on the market. It could be tested easily during one cultivation season by logging the data without real-time data transmission. 
Table 2: Ranking of longlisted techniques according to defined criteria. Number of components: many $=1$, some $=2$, few $=3$. Vulnerability to corrosion and biofouling: high $=1$, intermediate $=2$, none $=3$. Direct vs. derived measurement: derived $=1$, direct $=2$. Need for ground-truthing: a lot $=1$, intermediate $=2$, none $=3$. Availability: not available $=1$, available $=2$. Data analysis: difficult $=1$, challenging $=2$, easy $=3$. Dependence on Farm design: a lot $=1$, not $=2$. Distance of underwater data transfer: long $=1$, intermediate $=2$, short $=3$. Number/severeness of assumptions: high $=1$, intermediate $=2$, low $=3$. The criteria direct vs. derived measurement and distance of underwater data transfer were weighed double (see p. 15). The number/severeness of assumptions was weighed triple (see p.15).

\begin{tabular}{|c|c|c|c|c|c|c|c|c|c|c|c|}
\hline & $\begin{array}{l}\text { No. of } \\
\text { components }\end{array}$ & Corrosion & Biofouling & $\begin{array}{l}\text { Direct vs. } \\
\text { derived }\end{array}$ & $\begin{array}{l}\text { Ground- } \\
\text { truthing }\end{array}$ & Availability & $\begin{array}{l}\text { Data } \\
\text { analysis }\end{array}$ & $\begin{array}{l}\text { Farm } \\
\text { design }\end{array}$ & $\begin{array}{l}\text { Data transfer } \\
\text { distance }\end{array}$ & Assumptions & Sum \\
\hline Irradiance & 2 & 3 & 1 & 2 & 1 & 2 & 3 & 2 & 4 & 6 & 24 \\
\hline Pull & 2 & 1 & 3 & 4 & 1 & 1 & 3 & 1 & 6 & 6 & 28 \\
\hline Angle & 2 & 2 & 3 & 4 & 1 & 1 & 1 & 1 & 6 & 3 & 24 \\
\hline $\begin{array}{l}\text { Underwater } \\
\text { imagery }\end{array}$ & 2 & 2 & 1 & 4 & 2 & 1 & 1 & 2 & 4 & 9 & 28 \\
\hline Sonar & 2 & 2 & 1 & 4 & 1 & 2 & 2 & 2 & 6 & 9 & 31 \\
\hline $\begin{array}{l}\text { Aerial } \\
\text { imagery }\end{array}$ & 3 & 3 & 3 & 4 & 1 & 2 & 1 & 2 & 6 & 3 & 28 \\
\hline Model & 1 & 2 & 1 & 2 & 3 & 2 & 3 & 2 & 2 & 6 & 24 \\
\hline
\end{tabular}




\section{References}

Adams JM, Gallagher JA, Donnison IS (2009) Fermentation study on saccharina latissima for bioethanol production considering variable pre-treatments. J Appl Phycol 21:569-574. doi: 10.1007/s10811-0089384-7

Angell AR, Mata L, de Nys R, Paul NA (2016) The protein content of seaweeds: a universal nitrogen-to-protein conversion factor of five. J Appl Phycol 28:511-524. doi: 10.1007/s10811-015-0650-1

Barbier M, Charrier B, Arajuo R, et al (2019) Pegasus - Phycomorph european guidelines for a sustainable aquaculture of seaweeds, COST Action FA1406

Barros FCN, Da Silva DC, Sombra VG, et al (2013) Structural characterization of polysaccharide obtained from red seaweed Gracilaria caudata (J Agardh). Carbohydr Polym 92:598-603. doi: 10.1016/j.carbpol.2012.09.009

Bralatei E, Nekrosiute K, Ronan J, et al (2017) A field deployable method for a rapid screening analysis of inorganic arsenic in seaweed. Microchim Acta 184:1701-1709. doi: 10.1007/s00604-017-2151-1

Broch OJ, Alver MO, Bekkby T, et al (2019) The Kelp Cultivation Potential in Coastal and Offshore Regions of Norway. Front Mar Sci 5:529. doi: 10.3389/fmars.2018.00529

Broch OJ, Slagstad D (2012) Modelling seasonal growth and composition of the kelp Saccharina latissima. J Appl Phycol 24:759-776. doi: 10.1007/s10811-011-9695-y

Buck BH, Buchholz CM (2004) The offshore-ring: A new system design for the open ocean aquaculture of macroalgae. J Appl Phycol 16:355-368. doi: 10.1023/B:JAPH.0000047947.96231.ea

Buschmann AH, Camus C, Infante J, et al (2017) Seaweed production: overview of the global state of exploitation, farming and emerging research activity. Eur J Phycol 52:391-406. doi: 10.1080/09670262.2017.1365175

Chen H, Zhou D, Luo G, et al (2015) Macroalgae for biofuels production: Progress and perspectives. Renew Sustain Energy Rev 47:427-437. doi: 10.1016/j.rser.2015.03.086

Delauney L, Compare C, Lehaitre M (2010) Biofouling protection for marine environmental sensors. Ocean Sci 6:503-511. doi: 10.5194/os-6-503-2010

Dunn JT, Crutchfield HE, Gutekusnt R, Dunn AD (1993) Two Simple Methods for Measuring lodine in Urine. Thyroid 3:119-123. doi: 10.1089/thy.1993.3.119

Ganesan M, Reddy CRK, Jha B (2015) Impact of cultivation on growth rate and agar content of Gelidiella acerosa (Gelidiales, Rhodophyta). Algal Res 12:398-404. doi: 10.1016/j.algal.2015.10.001

Hafting JT, Critchley AT, Cornish ML, et al (2012) On-land cultivation of functional seaweed products for human usage. J Appl Phycol 24:385-392. doi: 10.1007/s10811-011-9720-1

Haldimann M, Alt A, Blanc A, Blondeau K (2005) lodine content of food groups. J Food Compos Anal 18:461-471. doi: 10.1016/j.jfca.2004.06.003

Hughes AD, Black KD, Campbell I, et al (2012) Does seaweed offer a solution for bioenergy with biological carbon capture and storage? Greenh Gases Sci Technol 2:402-407. doi: 10.1002/ghg

Hughes MF, Beck BD, Chen Y, et al (2011) Arsenic exposure and toxicology: A historical perspective. Toxicol Sci 123:305-332. doi: 10.1093/toxsci/kfr184

Jansen HM, Van Den Burg S, Bolman B, et al (2016) The feasibility of offshore aquaculture and its potential for multi-use in the North Sea. Aquac Int 24:735-756. doi: 10.1007/s10499-016-9987-y

Lehaitre M, Compère C (2008) BIOFOULING and UNDERWATER MEASUREMENTS. Prot sensors against fouling 463-493

Loureiro R, Gachon CMM, Rebours C (2015) Seaweed cultivation: Potential and challenges of crop domestication at an unprecedented pace. New Phytol 206:489-492. doi: 10.1111/nph.13278 
McGonigle C, Grabowski JH, Brown CJ, et al (2011) Detection of deep water benthic macroalgae using imagebased classification techniques on multibeam backscatter at Cashes Ledge, Gulf of Maine, USA. Estuar Coast Shelf Sci 91:87-101. doi: 10.1016/j.ecss.2010.10.016

McHugh D (2003) A guide to the seaweed industry

Milledge JJ, Smith B, Dyer PW, Harvey P (2014) Macroalgae-derived biofuel: A review of methods of energy extraction from seaweed biomass. Energies 7:7194-7222. doi: 10.3390/en7117194

Momber A (2011) Corrosion and corrosion protection of support structures for offshore wind energy devices (OWEA). Mater Corros 62:391-404. doi: 10.1002/maco.201005691

Ratcliff JJ, Wan AHL, Edwards MD, et al (2016) Metal content of kelp (Laminaria digitata) co-cultivated with Atlantic salmon in an Integrated Multi-Trophic Aquaculture system. Aquaculture 450:234-243. doi: 10.1016/j.aquaculture.2015.07.032

Ronan JM, Stengel DB, Raab A, et al (2017) High proportions of inorganic arsenic in Laminaria digitata but not in Ascophyllum nodosum samples from Ireland. Chemosphere 186:17-23. doi: 10.1016/j.chemosphere.2017.07.076

Schiener P, Black KD, Stanley MS, Green DH (2014) The seasonal variation in the chemical composition of the kelp species Laminaria digitata, Laminaria hyperborea, Saccharina latissima and Alaria esculenta. J Appl Phycol 27:363-373. doi: 10.1007/s10811-014-0327-1

Sondak CFA, Ang PO, Beardall J, et al (2017) Carbon dioxide mitigation potential of seaweed aquaculture beds (SABs). J Appl Phycol 29:2363-2373. doi: 10.1007/s10811-016-1022-1

Tonk L, Bernard M, Jansen H (2019) The use of video-techniques for monitoring and quantification of mobile fauna in marine cultivation systems

Uhl F, Bartsch I, Oppelt N (2016) Submerged kelp detection with hyperspectral data. Remote Sens 8:. doi: $10.3390 /$ rs8060487

van den Burg S, Stuiver M, Veenstra F, et al (2013) A Triple P review of the feasibility of sustainable offshore seaweed production in the North Sea

Van denHoek LS, Bayoumi EK (2018) Evaluating Seaweed as a Source of Protein in the Future of Food Production Worldwide. IOSR J Pharm Biol Sci 13:30-37. doi: 10.9790/3008-1302033037

Venkatesan J, Anil S, Kim SK (2017) Introduction to Seaweed Polysaccharides. Seaweed Polysaccharides Isol Biol Biomed Appl 1-9. doi: 10.1016/B978-0-12-809816-5.00001-3

Yebra DM, Kiil S, Dam-Johansen K (2004) Antifouling technology - Past, present and future steps towards efficient and environmentally friendly antifouling coatings. Prog Org Coatings 50:75-104. doi: 10.1016/j.porgcoat.2003.06.001

Young M, lerodiaconou D, Womersley T (2015) Forests of the sea: Predictive habitat modelling to assess the abundance of canopy forming kelp forests on temperate reefs. Remote Sens Environ 170:178-187. doi: 10.1016/j.rse.2015.09.020 